تاريخ الإرسال (29-12-2020)، تاريخ قبول النشر (22-02-2021)

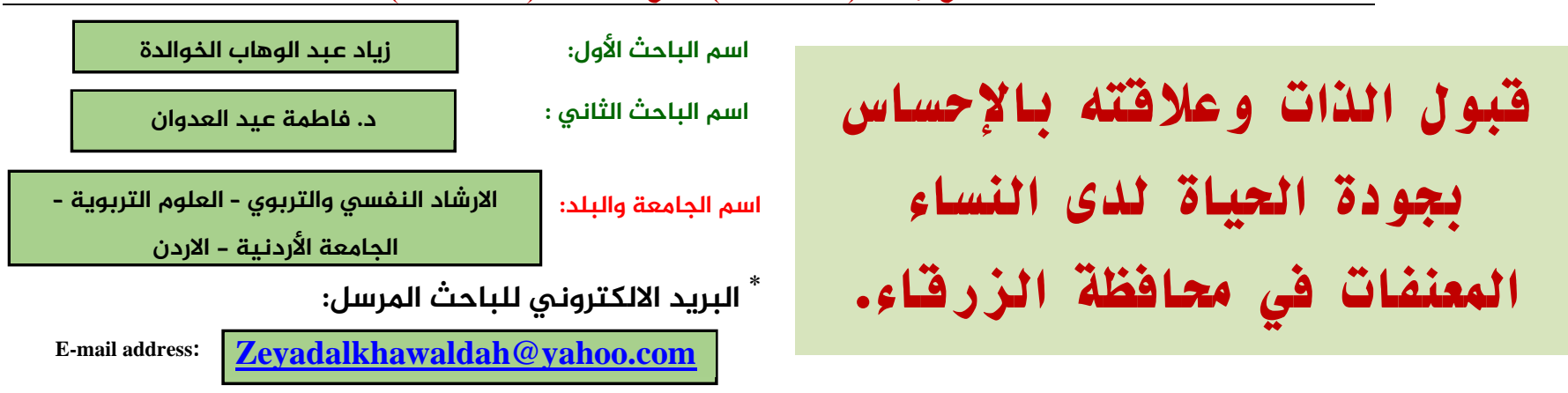

https://doi.org/10.33976/IUGJEPS.29.5/2021/16

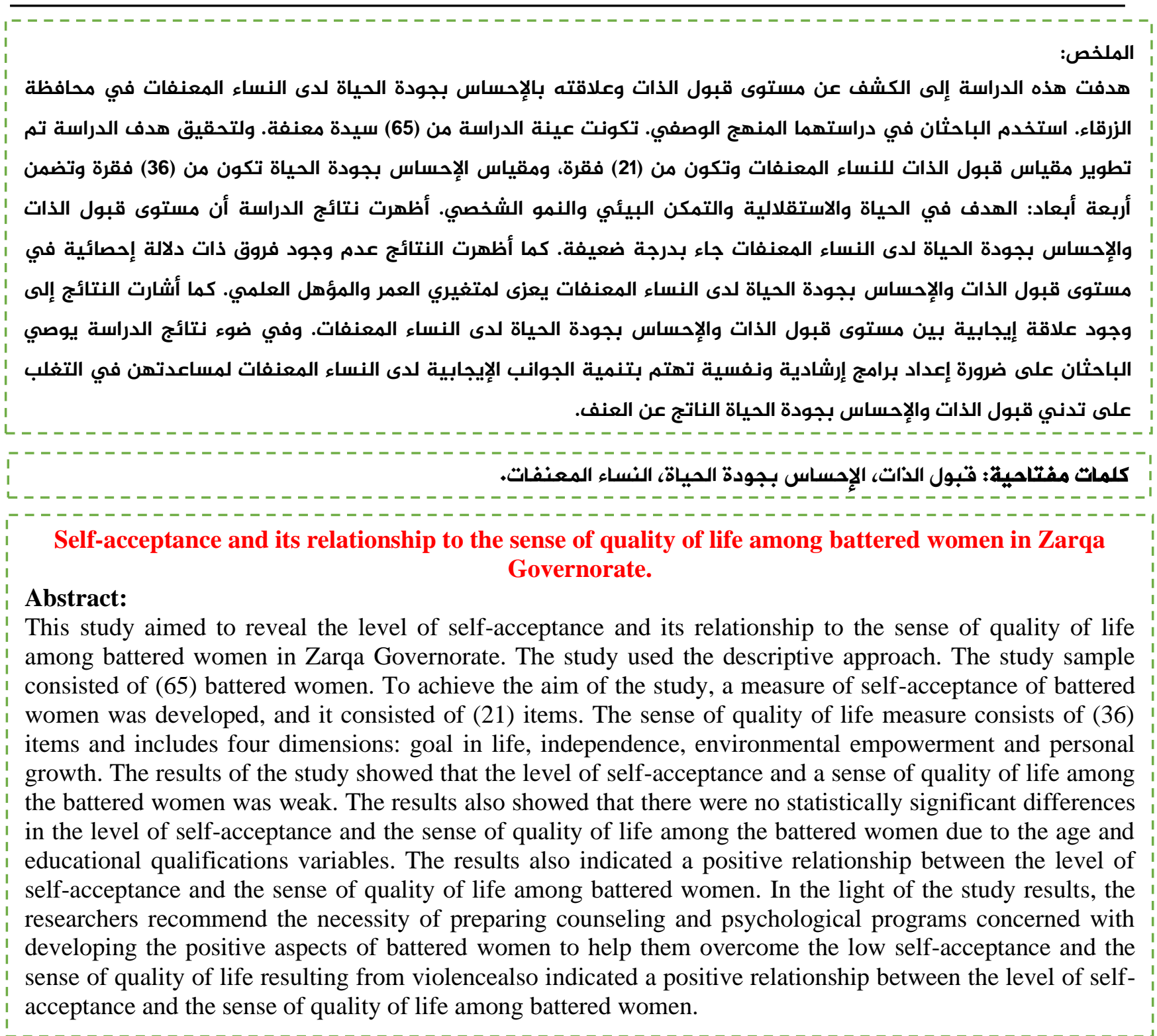

Keywords: Self-acceptance, a sense of quality of life, battered women. 
تعد قضية العنف ضد المرأة قضية عالمية تعاني منها النساء في جميع أنحاء العالم، ولا يكاد يخلو مجتمع منها, مهما

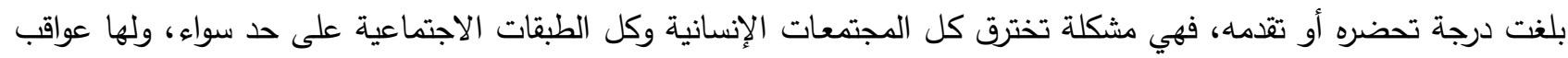
صحية عقلية على المدى القصير والبعيد على النساء، إلا أنها لم تحظ بالاهتمام على الرغم من أن التطورات الرئيسية في مجال التهاء

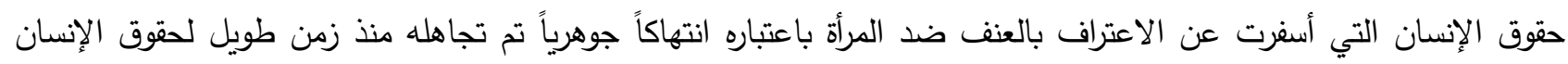
الخاصة بالمرأة.

ومع توسع الأبحاث النسوية الأخيرة حول العنف ضد المرأة أضحى التركيز أكبر على الأسباب السائدة للعنف ضد المرأة

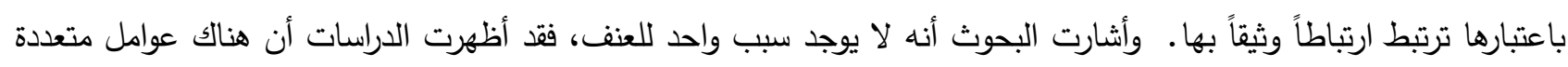
ترتبط بالسلوك العنيف، بما في ذلك العوامل البيولوجية، وكذلك العوامل الاجتماعية والسياسية وغيرها من العابية العوامل الثقافية والبيئية، ولا يمكن تجاهل قضايا مثل الفقر والطبقة والجنس (Michael, 2014). وتفترض منظمة الصئل الصحة العالمية أن القوة والسيطرة هي المحفزات الكامنة وراء عنف الرجال تجاه النساء وأنهم يستخدمون مجموعة من الاستراتيجيات لتأكيد تلك القوة والسيطرة. ومن هنا تعرف منظمة الصحة العالمية ( World Health Organization, 2016 ) العنف ضد المرأة بأنه: أي سلوك من قبل شريك العكاه حميم حالي أو سابق يتسبب في ضرر بدني أو جنسي أو نفسي ، بما في ذلك أعمال العدوان الجسدي والإكراه الجنسي والإيذاء

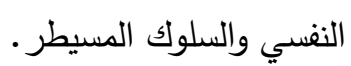

Gupta, ) وقد أشارت العديد من الدراسات إلى آثار العنف السلبية على حياة النساء، بما في ذلك مواقعهن الاقتصادية

Beydoun, Williams, Beydoun, Eid, \& والصحة (Larsen, Krohn, Püschel \& Seifert, 2014 ؛et al, 2017

Gilroy,et al, ) (Zonderman, 2017)

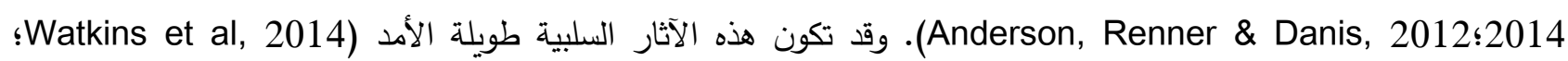

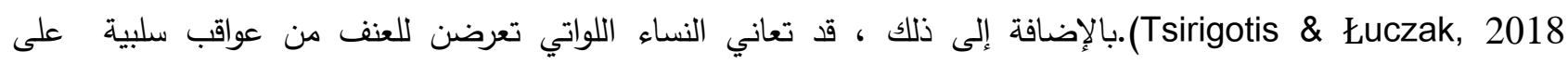

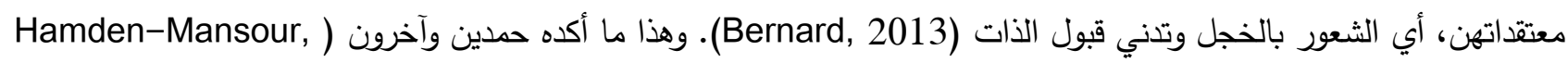
(et al, 2011

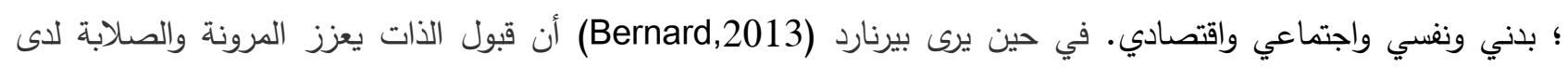

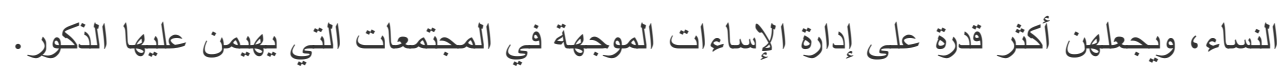

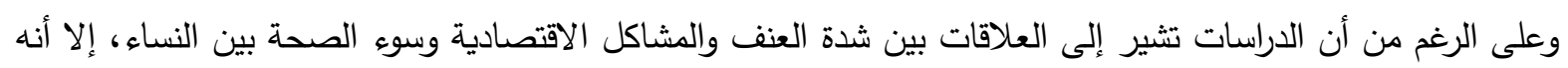

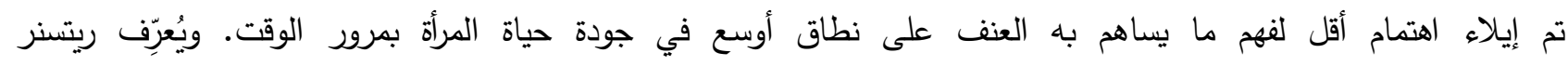
وآخرون (Ritsner, et al,2002: 1533 جودة الحياة على أنه "إحساس المرء بالرفاهية والقدرة على العمل في مختلف مجالات

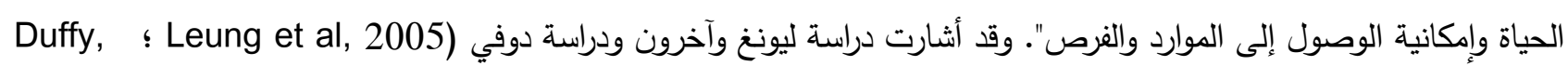

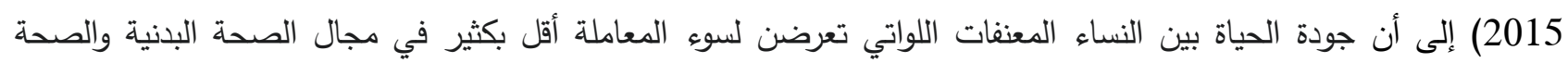
النفسية والعلاقات الاجتماعية والبيئة. ويؤكد ريزو (Rizo, 2016) إلى أن تعرض النساء للإساءة وسوء نوعية الحياة يستمر ويواجهن العديد من تحديات الحياة بما في ذلك المشاكل المالية والصحية وقضايا الأمن والسلامة.

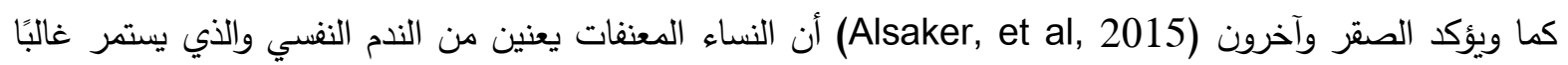
لفترات طويلة. إضافة إلى إحساس المرأة بتدني قيمة الذات من خلال تلقيها باستمرار رسالة تفيد بأنها أقل قيمة من خلال الإساءة اللفظية. وقد تتدهور الحالة النفسية للنساء من خلال وصفهن بأنهن غبيات، أو لا قيمة لهن أو غير كفؤات في كل ما يفعلن. وهذا

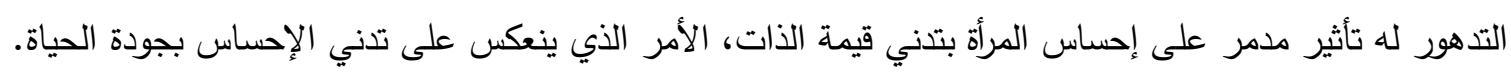


ويرى غودمان سميث (Goodman \& Smyth,2011) أن المرأة تسعى بنشاط وتستخدم استراتيجيات مختلفة للتعامل مع العنف في حياتها منها الانفصال عن الشريك المسيء، ويُظر إليه على أنه حل مشترك للعنف يسمح للنساء بخلق حياة جديدة

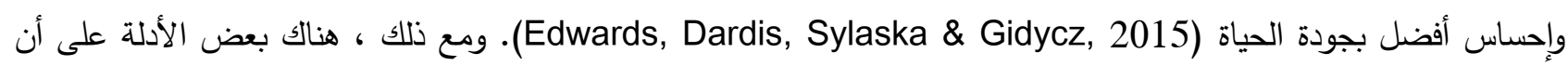
الانفصال لا ينهي الكثير من المشاكل التي تواجهها النساء (Alhalal, Ford-Gilboe, Kerr\& Davies, 2012). ونظرًا لما يتمتع به هذا الموضوع من الأهمية، فقد حفل الأدب التربوي بالعديد من الدراسات التي بحثت في موضوعات التهات

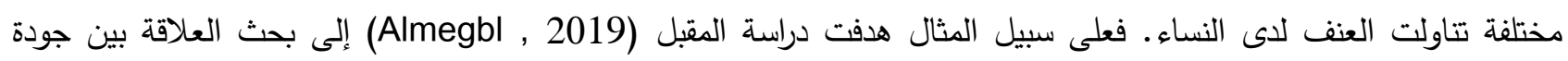
الحياة وأعراض اضطراب ضغوط ما بعد الصدمة لدى النساء المعنفات في ضوه متغيرات ( العمر، الحالة الاجتماعية، المؤهل

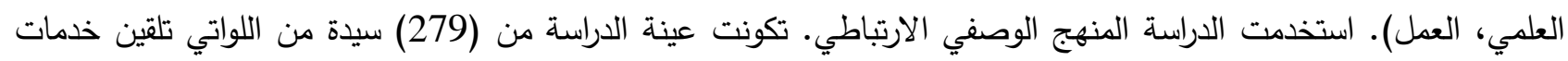

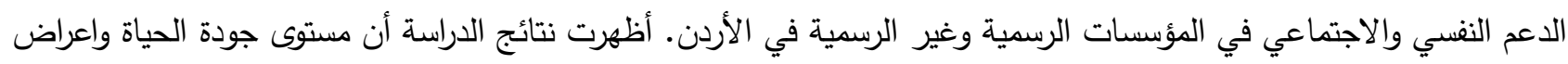
اضطراب ضغوط ما بعد الصدمة كان متوسطاً.

وهدفت دراسة الصقر وآخرون (2018) Alsaker ,et al, إلى استكثاف عنف الشريك الحميم المرتبط بانخفاض جودة الحياة. استخدمت الدراسة المنهج الوصفي. تكونت عينة الدراسة من النساء اللواتي يطلبن المساعدة " بعد إساءة معاملة الشريك

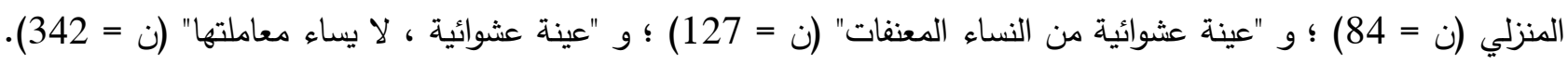
أظهرت نتائج الدراسة أن العنف النفسي والجسدي أقل بين النساء اللواتي يطلبن المساعدة بسبب العنف. كما أظهرت النتائج أن أن أنساء عنف الشريك الحميم يرتبط بشكل واضح بانخفاض جودة الحياة. في حين هدفت دراسة ربابعه (2017) إلى البحث في علاقة جودة الحياة بالقبول الاجتماعي واستراتيجيات المواجهة لاى النساء المعنفات. استخدمت الدراسة المنهج الوصفي. تكونت عينة الدراسة من (107) أنثى معنفة في مدينة إربد. أظهرت نتائج الدراسة أن مستوى جودة الحياة جاء بدرجة ضعيفة باستثاء بعدي النمو الثخصي وتقبل الذات قد جاءا بدرجة متوسطة.

وقام لوسينا وآخرون Lucena, et al, بدراسة هدفت إلى استكشاف الارتباط بين العنف المنزلي وجودة حياة المرأة. استخدمت الدراسة المنهج الوصفي. تكونت عينة الدراسة من (424) امرأة (18) سنة فما فوق اختيرت بالطريقة الطبقية

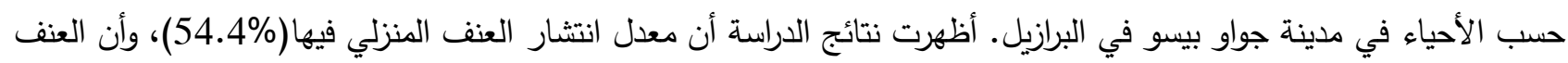

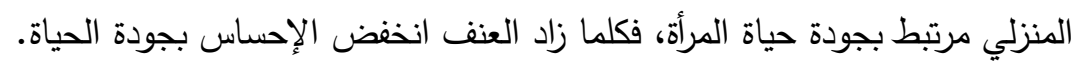
كما قام تافولي وآخرون (2016) Tavoli, et al, بدراسة هدفت إلى فحص جودة الحياة لاى مجموعة من النساء اللاتي تعرضن للعنف المنزلي أثناء الحمل. استخدمت الدراسة المنهج الوصفي والنوعي. تكونت عينة الدراسة من (230) من النساء الحوامل اللواتي يلتحقن بمستشفى تعليمي في لورستان، إيران. أظهرت نتائج الدراسة أن العنف المنزلي ضد النساء أنساء أثناء الحمل ارتبط ارتباط سلبي كبير بجودة الحياة. بينما دراسة غراشه وآخرون Gharacheh, et al, 2016 هدفت إلى استكثاف العنف المنزلي أثناء الحمل وعلاقته بجودة الحياة. استخدمت الدراسة المنهج الوصفي. تكونت عينة الدراسة من(341) امرأة بعد الولادة والتي أشارت إلى مراكز الرعاية

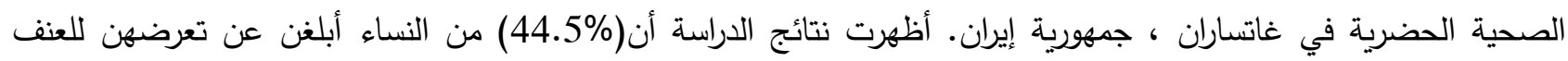
المنزلي أثناء الحمل، وسجلت جميع المقاييس الفرعية لجودة الحياة بما في ذلك أبعاد الصحة البدنية والنفسية درجة أقل لاى النساء المعنفات مقارنة بالنساء غير المعنفات.

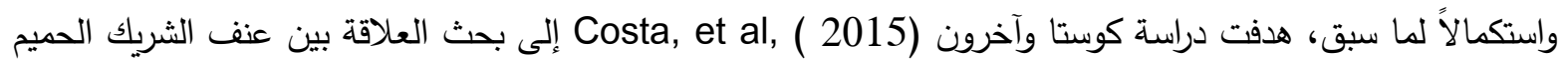
على جودة الحياة لدى الرجال والنساء. استخدمت الدراسة المنهج الوصفي والنوعي. تكونت عينة الدراسة من (3496) مشاركاً ، 353 IUG Journal of Educational and Psychology Sciences (Islamic University of Gaza) / CC BY 4.0 
(1470) من الرجال و(2026). أظهرت نتائج الدراسة أن متوسط المكون البدني والعقلي المرتبط بجودة الحياة منخف لدى مقار النساء مقارنة بالرجال.

وبناءاً على ما سبق، يتبين أن أحد أبرز الأمور التي تواجه المرأة وتتعكس على حياتها العاطفية والجسمية والاجتماعية العنف؛ لذا جاءت هذه الدراسة للتعرف على العلاقة بين قبول الذات والإحساس بجودة الحياة لدى النساء المعنفات في محافظة

مشكلة الدراسة:

العنف مشكلة عالمية يمكن أن تدمر تكوين المجتمع، ويمكن أن تشكل تهديداً للحياة والصحة والسعادة للأفراد، ويؤكد (Cases, Ruiz-Cantero, Escriba-Aguir \& Miralles, 2010)

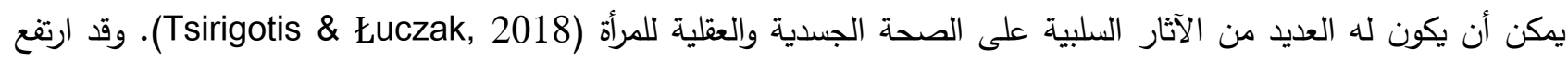
العنف تجاه النساء في معظم المجتمعات حيث أن (10\% - 69\% من من من النساء تعرضن للعنف الجسدي في مرحلة ما من

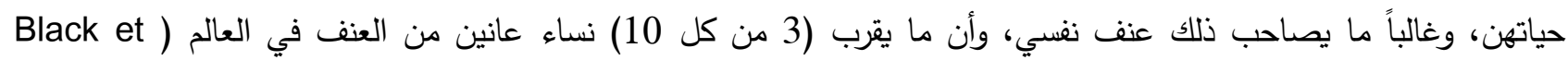

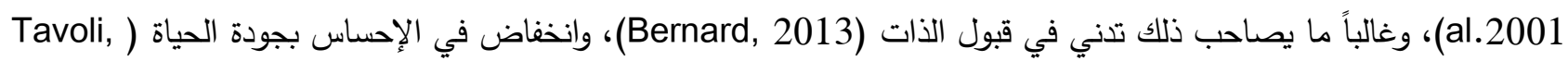

.(et al, 2016

وقد أفادت مراجعة نشرتها منظمة الصحة العالمية في عام (2013) لدراسات من (86) دولة، وبيانات من (155) دراسة، أن الاتتشار العالمي للعنف الجسدي و/ أو الجنسي للشريك بين جميع النساء كان (30\%)، حيث أفاد ما يقرب (37\%) من النساء اللاتي سبق لهن شراكة بأنهن تعرضن لعنف الشريك الجسدي و/ أو الجنسي في مرحلة ما من حياتهن ( Tavoli, et

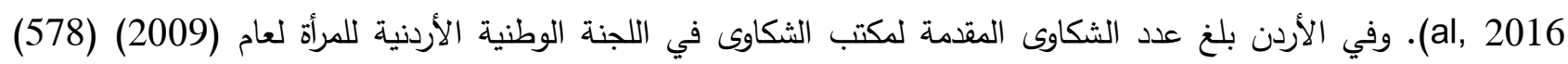

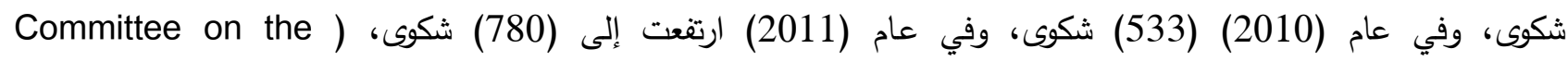
2012, Elimination of Discrimination against Women). ويشير المسح الذي قام به المجلس الوطني لشؤون الاسرة لعام (2018) بأن (60\%) من هذه الاسرة تعرض فيها رب الأسرة للعنف في صغره. وخلصت نتائج مسح السكان والصحة الأسرية في الأردن (2017-2018) بالتعاون مع الوكالة الأمريكية للتمية الدولية، ومنظمة الأمم المتحدة للطفولة ( اليونسيف)،

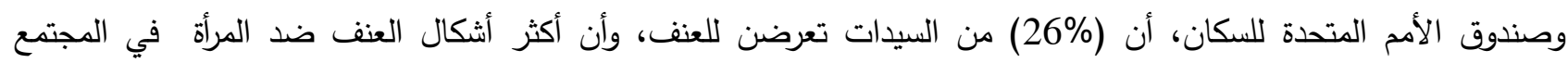
الأردني هو العنف النفسي، يليه العنف الجسدي، ثم العنف الجنسي. لكن ليس هذا هو الواقع؛ لأن كثير من النساء اللواتي

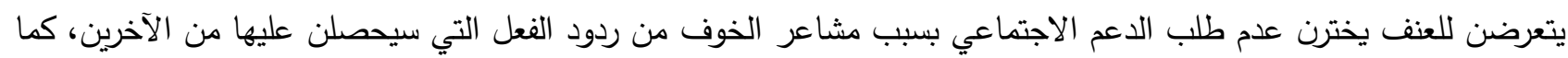

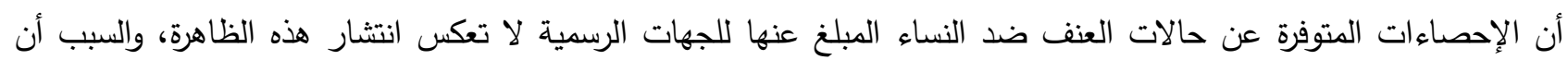
معظم ضحايا العنف لا يطلبن المساعدة (2018 (Barnett, 2001 (Department of Statistics)؛ لذا تتمثل مشكلة الدراسة الإسة في أن هناك تزايد كبير في أعداد وحالات العنف ضد المرأة في المجتمع الأردني، حيث اصبحت ظاهرة مقلقة لجميع الفئات. ومن هنا تظهر مشكلة الدراسة في التعرف على العلاقة بين قبول الذات والإحساس بجودة الحياة لدى النساء المعنفات في محافظة الزرقاء من خلال الإجابة عن الأسئلة الآتية:

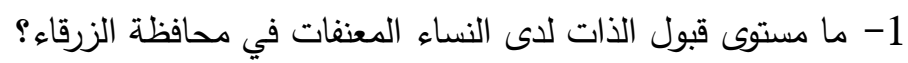

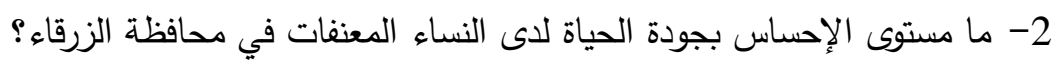

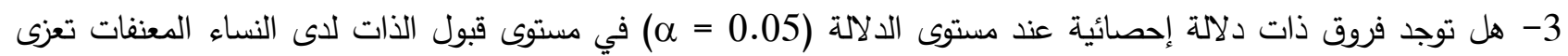

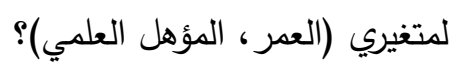


4- هل توجد فروق ذات دلالة إحصائية عند مستوى الدلالة (1) (ل05 = م) في مستوى الإحساس بجودة الحياة لدى النساء

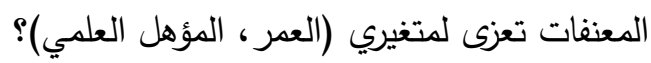
5- هل هناك علاقة دالة احصائياً عند مستوى الدلالة (0.05 = م) بين قبول الديوي الذات والإحساس بجودة الحياة لدى النساء

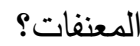
أهداف الدراسة: هدفت الدراسة الحالية إلى ما يأتي: - - الكثف عن مستوى قبول الذات والإحساس بجودة الحياة لاى النساء المعنفات في محافظة الزرقاء.

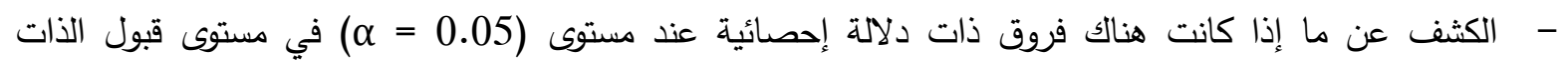
والإحساس بجودة الحياة تعزى لمتغيري (العمر ، المؤهل العلمي).

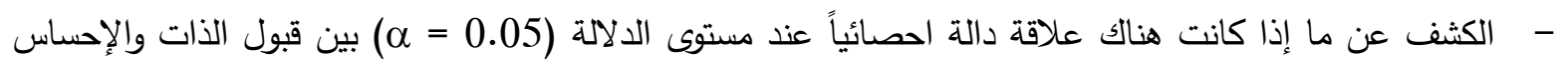
بجودة الحياة لاى النساء المعنفات.

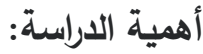
تكمن أهمية الدراسة النظرية والتطبيقية فيما يلي: أولاً: الأهمية النظرية: - - ندرة الدراسات التي اهتمت بموضوع الدراسة -حسب علم الباحثان - فعلى الرغم من إجراء العديد من الدراسات والأبحاث الميدانية التي تتاولت متغيري قبول الذات والإحساس بجودة الحياة، إلا أنه لم توجد دراسات تلتاولت العلاقة بين قبول إنبول الذات والإحساس بجودة الحياة، ومن هنا كانت الحاجة لمثل هذه الدراسة. - - توجيه الأنظار للاهتمام بدور المرأة الذي تلعبه في بناء المجتمع، باعتبارها الدعامة الأساسية في بناء الأسرة، وهي ذات قيمة كبيرة إذا تم رعايتها وأعطيت الحق في العيش وممارسة أدوارها بحرية. - الاهتمام المتصاعد بالمرأة والعمل على تمكينها والتخلص من ضعفئها ومشكلاتها لتأخذ المكانة اللائقة بإنسانيتها وبصفتها شريك الرجل الاستراتيجي في عملية التتمية وأبعادها كافة.

ثانياً: الأهمية التطبيقية: تكمن أهمية الدراسة التطبيقية فيما يلي: - - النتائج التي ستتوصل إليها الدراسة يتوقع لها أن تتير الطريق أمام المرشدين والمرشدات الذين يتعاملون مع النساء المعنفات في إرشادهن لتحسين قبول الذات والإحساس بجودة الحياة لديهن. - - إمكانية استفادة المؤسسات الاجتماعية والجمعيات من نتائجها في وضع الخطط والسياسات ووضع البرامج التربوية والاجتماعية اللازمة لرعاية النساء المعنفات. حدود الدراسة: تم تطبيق الدراسة في ضوء الحدود الآتية: - الحدود البشرية: اقتصرت الدراسة الحالية على عينة من النساء المعنفات من جمعية ( أثر للتمية الثبابية ) في الرصيفة بمحافظة الزرقاء. - الحدود المكانية: تحدد الاطار الجغرافي لهذه الدراسة في منطقة الرصيفة في محافظة الزرقاء وبالتحديد جمعية (أثر للتنمية الثبابية). - الحدود الزمانية: أجريت هذه الدراسة خلال الفترة 1/ 1920 / 2020 ولغاية 11/1/ 2020. 
قبول الذات Self-Acceptance: موقف يتبناه الثخص تجاه نفسه باعتباره فردًا معقدًا وفريدًا ولكنه عرضة للخطأ؛ ومع ذلك ،

لا يوجد تقييم أو حكم على الذات (Bernard, 2013). ويُعرّف إجرائياً بأنه: الدرجة التي حصلت عليها المستجيبة من أفراد عينـة الدراسة بأسلوب التقدير الذاتي لمستوى قبول

الذات لديها على المقياس المستخدم في الدراسة الحالية. جودة الحياة Quality Of Life: "تصورات الأفراد لموقفهم في الحياة في سياق نظم الثقافة والتيم التي يعيشون فيها، وفيما يتعلق

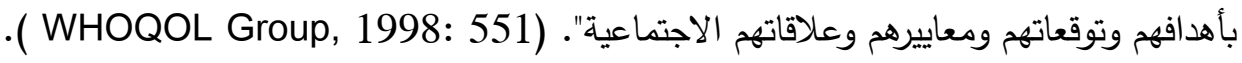
وتُعرّف إجرائياً بأنها: الدرجة التي حصلت عليها المستجيبة من أفراد عينة الدراسة بأسلوب التقدير الذاتي لمستوى الإحساس بجودة الحياة لديها على المقياس المستخدم في الدراسة الحالية. العنف ضد النساء Violence Against Women : جميع أثكال العنف البدني أو الجنسي أو النفسي أو الاقتصادي الذي يحدث داخل الأسرة أو بين الأزواج أو الشركاء السابقين أو الحاليين (Council of Europe, 2011). اجراءات الاراسة منهج الإِراسة: اتبعت الدراسة المنهج الوصفي التحليلي لملاءمته لطبيعة الدراسة. مجتمع الآّراسة: تكون مجتمع الدراسة من الزوجات المعنفات المسجلات في جمعية أثر للتنمية الثبابية في لواء الرصيفة التابع لمحافظة الزرقاء والبالغ عددهن (85) سيدة ، وفق الإحصاءات الرسمية للجمعية للعام 2021/2020. عينة الآرّاسة: تمثلت عينة الدراسة من جميع الزوجات المعنفات بعد استبعاد عينة الصدق والثبات بلغ عددهن (65) سيدة معنفة،

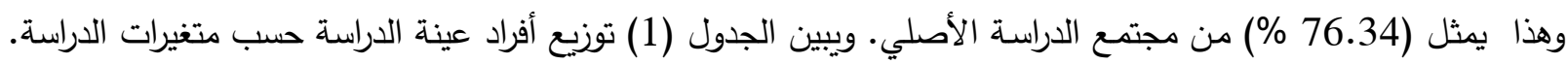

\begin{tabular}{|c|c|c|c|}
\hline \multicolumn{4}{|c|}{ الجدول (1): توزيع أفراد عينة الدراسة حسب متغيري (العمر، المؤهل العلمي). } \\
\hline النسبة المئوية & العدد & الفئة & المتغير \\
\hline$\% 38.5$ & 25 & أقل من 30 سنة & \multirow{4}{*}{ 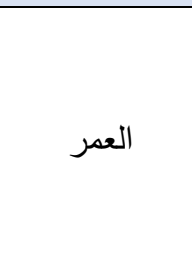 } \\
\hline$\% 41.5$ & 27 & من 31الى 40 سنة & \\
\hline$\% 20.0$ & 13 & أكثر من 41 سنة & \\
\hline$\% 100$ & 65 & الكلي & \\
\hline$\% 20.0$ & 13 & اساسي & \multirow{4}{*}{ 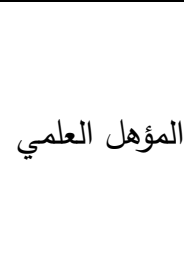 } \\
\hline$\% 53.8$ & 35 & ثانوي & \\
\hline$\% 26.2$ & 17 & جامعي & \\
\hline$\% 100$ & 65 & الكلي & \\
\hline
\end{tabular}

أدوات الدراسة: اولاً: مقياس قبول الذات: قام الباحثان بتطوير مقياس قبول الذات للنساء المعنفات بعد مراجعة المصادر المتوفرة من الأدب التربوي والدراسات

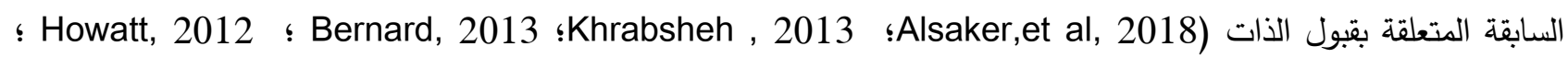
Fung, 2011 )، وتكون المقياس من جزأين: الجزء الأول يتعلق بالمعلومات الديمغرافية وتتمثل؛ (العمر، المؤهل العلمي)، والجزء الثاني تكون من ( 25) فقرة بصورته الأولية. 
للتأكد من الصدق الظاهري للمقياس، تم عرضه على عدد من المتخصصين في مجال الإششاد النفسي وعلم النفس والقياس والتقويم في الجامعات الأردنية بلغ عددهم (10) محكمين؛ إذ تم إعادة صياغة ودمج وحذف بعض الفقرات، وتم الإبقاء

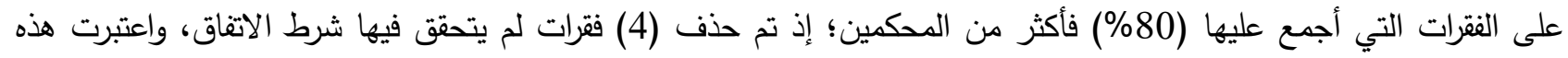
الإجراءات دلالة صدق ظاهري للأداة. كما تم التحقق من صدق البناء للمقياس، وذلك بتطبيقه على عينة استطلاعية بلغت (20)

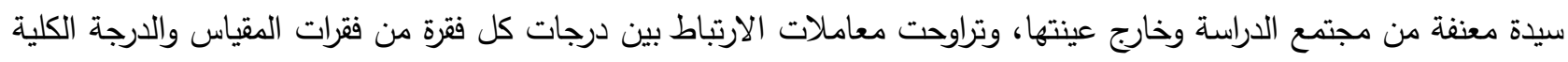
للمقياس (0,5- 0,81) وهي دالة إحصائياً عند مستوى الدلالة (0.05 = م) مما يدل على تمتع المقياس بصدق عندر عالٍ وملائم لأغراض الدراسة.

ثبات مقياس قبول الذات:

تم توزيع المقياس على عينة استطلاعية من مجتمع الدراسة وخارج عينتها والمتمثلة بـ (20) سيدة معنفة، وبعد أسبوعين

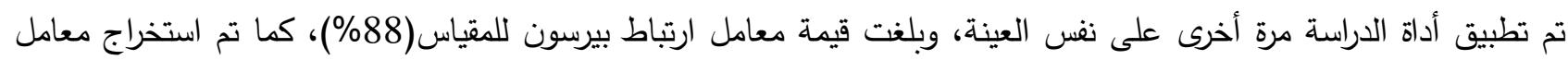
الاتساق الداخلي بالاعتماد على اختبار كرونباح -الفا (Cronbach Alpha) وبلغت قيمة معامل الاتساق الداخلي للمقياس (90\%). مما يدل على تمتع المقياس بثبات عالٍ وملائم لأغراض الدراسة. وبهذا تكون المقياس في صورته النهائية من (21)

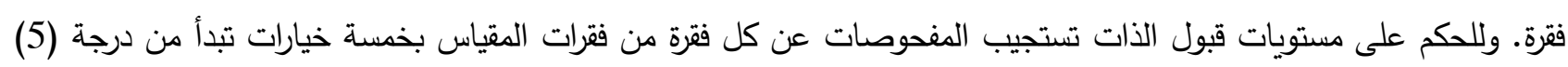

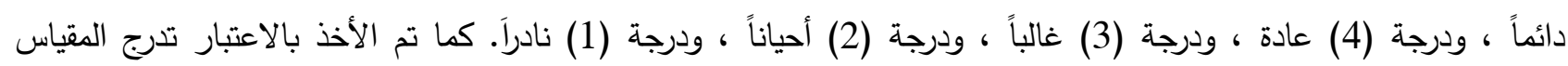

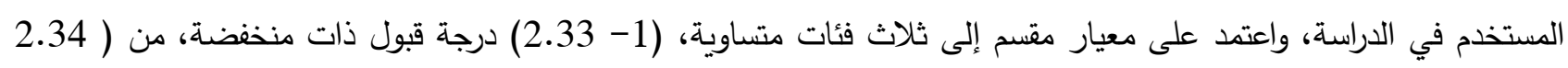

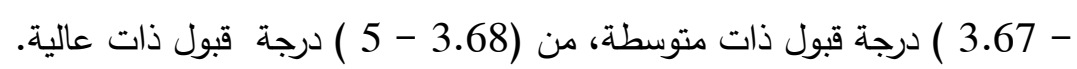

ثانياً: مقياس الإحساس بجودة الحياة:

قام الباحثان بتطوير مقياس الإحساس بجودة الحياة لاى النساء المعنفات بعد مراجعة المصادر المتوفرة من الأدب

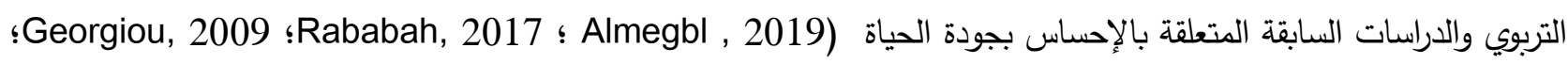
Ferriss, 2010 الجزء الأول يتعلق بالمعلومات الديمغرافية وتتمثل؛ (العمر، المؤهل العلمي). والجزء الثاني تكون من (38) فقرة بصورته الأولية موزعة على أربعة أبعاد، هي: بعد الهدف في الحياة (9) فقرات، بعد الاستقلالية (9) فقرات، بعد التككن البيئي (10) فقرات، بعد النمو الشخصي (10) فقرات.

صدق مقياس الإحساس بجودة الحياة: للتأكد من الصدق الظاهري للمقياس، تم عرضه على عدد من الإتخصصين فئ في مجال الإششاد النفسي وعلم النفس

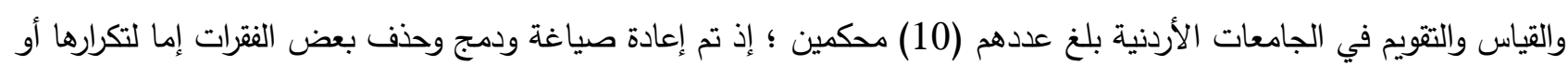
تصنيفها في أبعاد أخرى، وتم الإبقاء على الفقرات التي أجمع عليها (80\%) فأكثر من المحكمين؛ إذ تم حذف فقرة من بعد الهدف في الحياة، وفقرة من بعد الاستقلالية لم يتحقق فيها شرط الاتفاق، واعتبرت هذه الإجراءات دلالة صدق الإنقاه ظاهري للأداة. كما تم التحقق من صدق البناء للاستبيان، وذلك بتطبيقه على عينة استطلاعية بلغت (20) سيدة معنفة من مجتمع الدراسة وخارج عينتها، وقد تراوحت قيم دعاملات ارتباط فقرات مجال الهدف في الحياة بين (0.38 - 0.84) مع مجاءت مجالها، وبين (0.42)

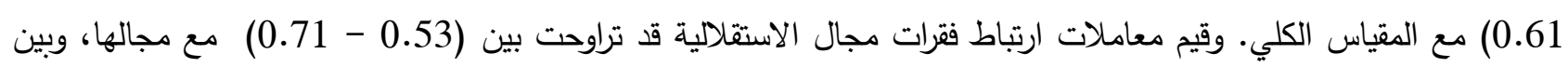

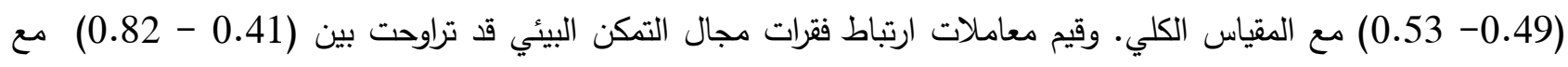

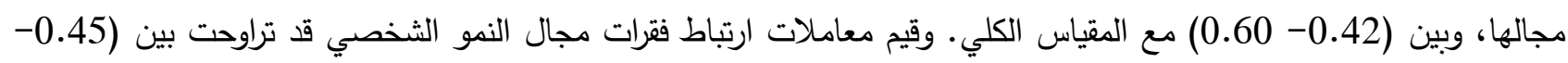
357 IUG Journal of Educational and Psychology Sciences (Islamic University of Gaza) / CC BY 4.0 
كمكا 0.69) مع مجالها، وبين (0.40-0.72) مع المقياس الكلي. كما تراوحت معاملات الارتباط لأبعاد المقياس وعلى المقياس

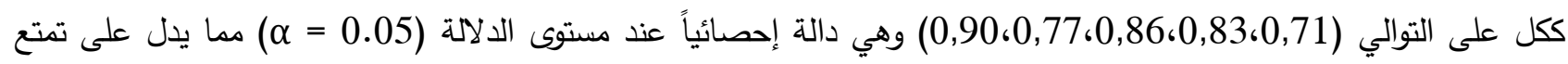
المقياس بصدق عالٍ وملائم لأغراض الدراسة.

ثبات مقياس الإحساس بجودة الحياة:

تم توزيع المقياس على عينة استطلاعية من مجتمع الدراسة وخارج عينتها والمتمثلة بـ (20) سيدة معنفة، وبعد أسبوعين

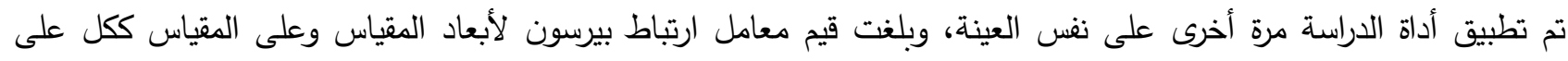

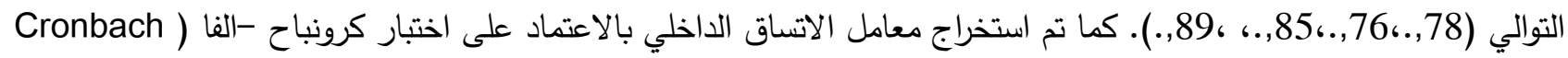
لكل بعد من أبعاد المقياس، وبلغت قيم معاملات الاتساق الداخلي لأبعاد المقياس وعلى المقياس ككل على التوالي التئي (Alpha

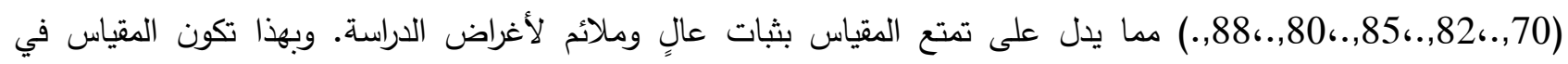

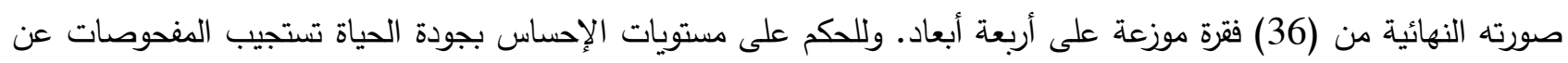

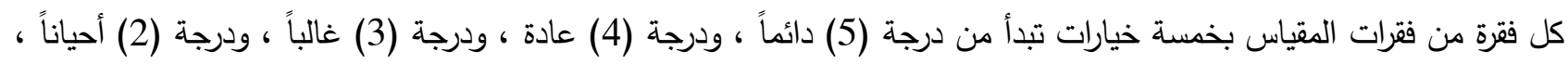

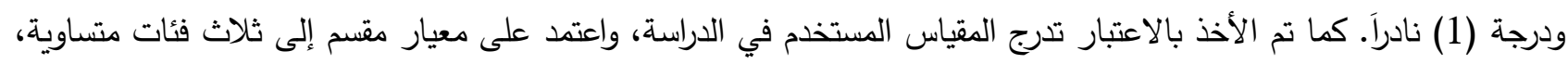

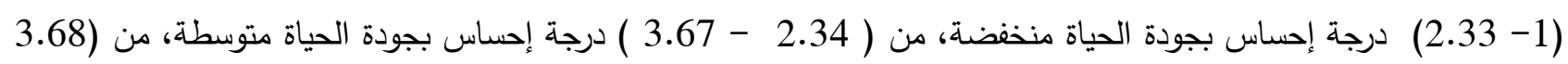
- 5 - (1) درجة إحساس بجودة الحياة عالية.

\section{نتائج الاراسة ومناقثتها}

النتائج المتعلقة بالسؤال الأول: ما مستوى قبول الذات لاى النساء المعنفات في محافظة الزرقاء؟

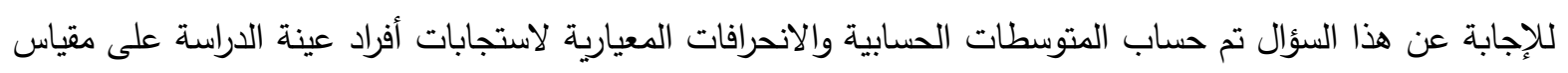
قبول الذات. وتبين أن أفراد العينة امتلكوا مستويً ضعيف من قبول الذات؛ إذ بلغ المتوسط الحسابي لمقياس قبول الذات (2.30)

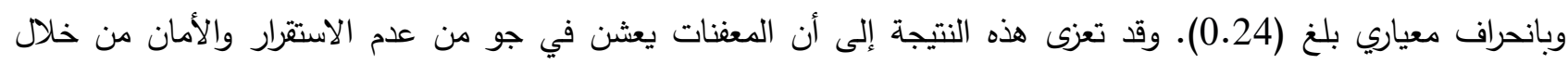

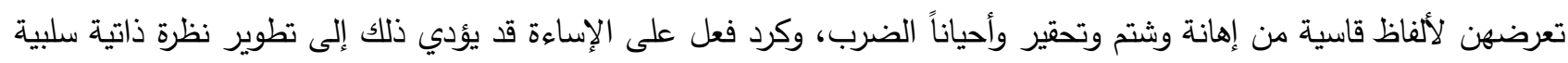

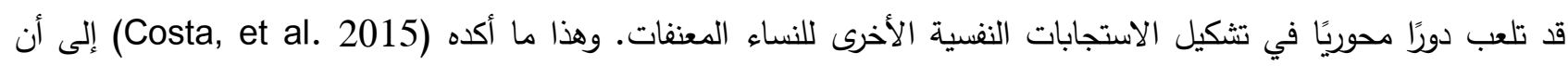

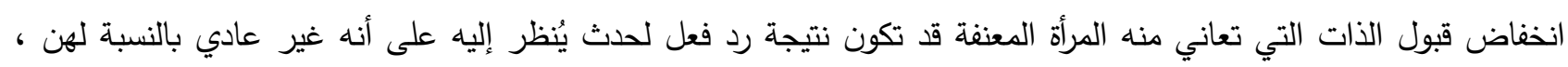

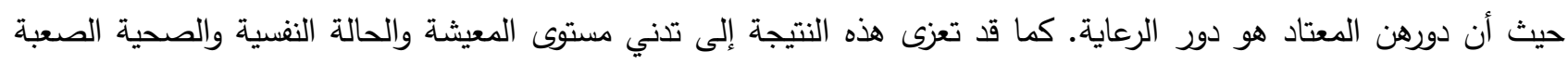
التي تعاني منها المعنفات، وضعف العلاقات والذي يعد مؤشراً لتدني وجود قبول اجتماعي من الأفراد المحيطين بهن مها يؤدي لـوني إلى عدم القدرة على حل المشكلات الشخصية ووجود مستويات مرتفعة من الاضطرابات النفسية والانفعالية، فقد يكن أكثر عرضة الأني

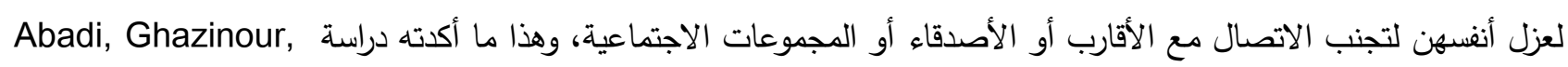
(Nojomi \& Richter , 2012) من أن النساء المعنفات قد يتعرضن للوصم من قبل أفراد أسرهم لانتهاكهم معايير اجتماعية

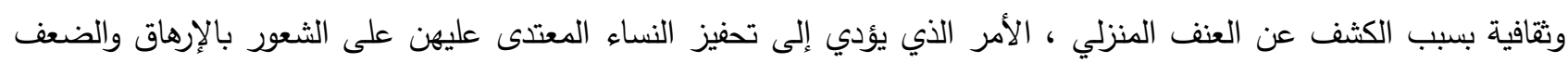
وانخفاض الأداء البدني والذي ينعكس على شعورهن بمستوى متدنٍ من قبول الذات. وتتفق نتيجة هذه الدراسة مع نتيجة دراسة

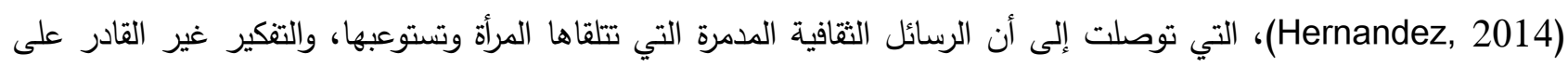

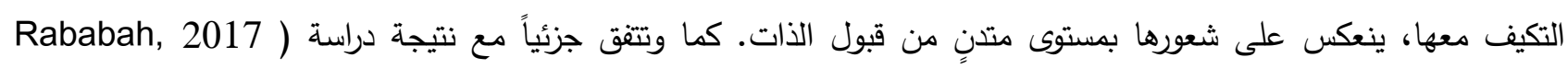

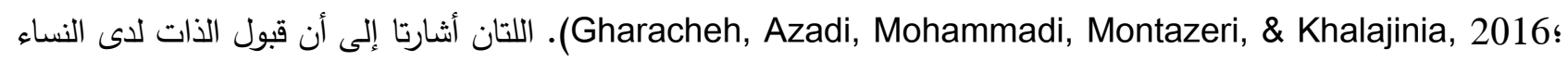


النتائج المتعلقة بالسؤال الثاني: ما مستوى الإحساس بجودة الحياة لاى النساء المعنفات في محافظة الزرقاء؟ للإجابة عن هذا السؤال تم حساب المتوسطات الحسابية والانحرافات المعيارية لاستجابات أفراد عينة الدراسة على كل بعد من أبعاد مقياس مستوى لإسواء الإحساس بجودة الحياة وعلى المقياس ككل. والجدول (2) يوضح ذلك.

\begin{tabular}{|c|c|c|c|c|}
\hline \multicolumn{5}{|c|}{ الجدول (2): المتوسطات الحسابية والانحرافات المعيارية لاستجابات أفراد عينة الاراسة على كل بعد من أبعاد } \\
\hline بجوجة الإحساس & الرتبة & الانحراف المعياري & المتوسط الحسابي & البعد \\
\hline ضعيفة & 1 & 0.23 & 2.23 & الهدف في الحياة \\
\hline ضعيفة & 3 & 0.29 & 2.17 & الاستقلالية \\
\hline ضعيفة & 2 & 0.24 & 2.19 & التمكن البيئي \\
\hline ضعيفة & 4 & 0.31 & 2.16 & النمو الشخصي \\
\hline ضعيفة & ----- & 0.14 & 2.18 & الكلي \\
\hline
\end{tabular}

يبين الجدول (2) أن أفراد العينة امتلكوا مستوئً ضعيف من الإحساس بجودة الحياة ؛ إذ بلغ المتوسط الحسابي للمقياس ككل (2.18) وبانحراف معياري بلغ (0.14). وجاء ترتيب الأبعاد كالآتي: ( الهدف في الحياة في المرتبة الأولى، والتمكن البيئي في لئي

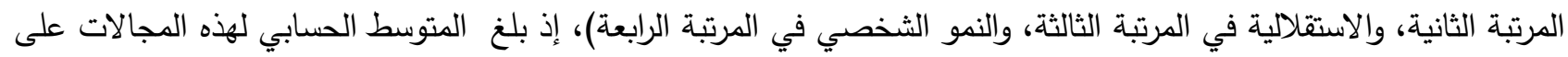

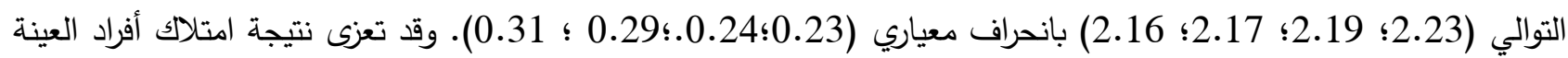

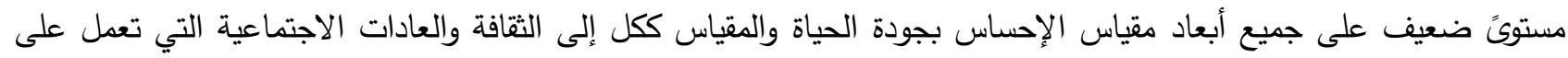

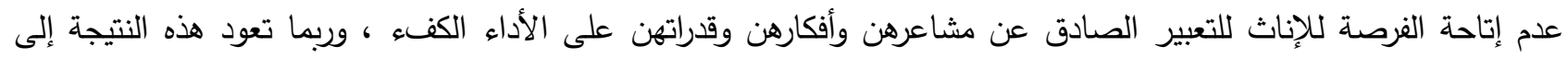

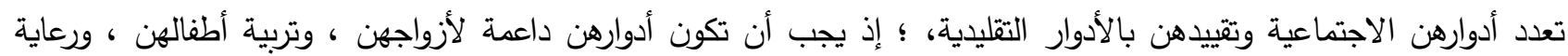

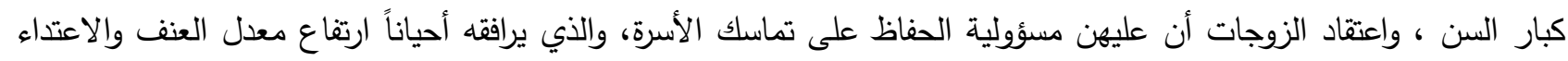

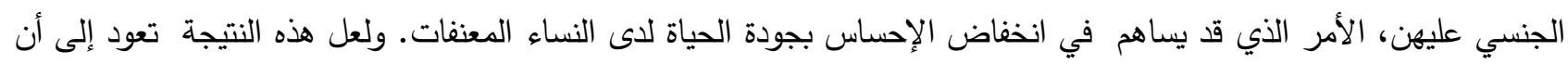

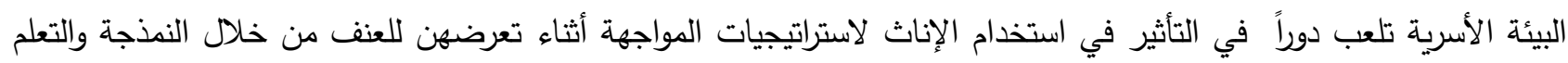

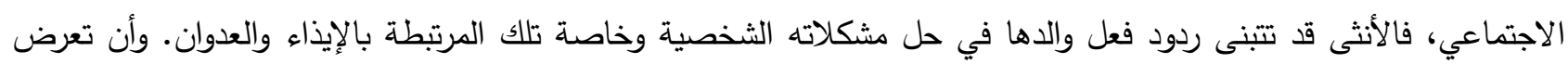
الإناث لمظاهر العنف والعدوانية داخل المنزل قد يقودهن إلى الثعور بالذنب والإحباط الناتج عن الثعور بالعجز وانعدام القدرة على إحداث تغييرات في حياتها الاجتماعية أو التكيف معه أو تفسيره، خاصة وأن افتقار الأسر المعنفة لأساليب التنشئة الاجتماعية المعززة للنمو المعرفي للإناث قد يعيق قدرتهن على استخدام استراتيجيات المواجهة الفعالة، مما قد يساهم في انخفاض Alsaker, Moen, Morken, \& Baste, ) الإحساس بجودة الحياة لديكن. وتتقق نتيجة هذه الدراسة مع نتيجة دراسة فئسة .(Hernandez, 2014 ؛Lucena, Vianna, Nascimento, Campos, \& Oliveira, 2017؛2018

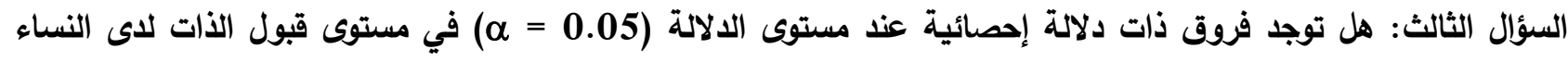
المعنفات تعزى لمتغيري (العمر، المؤهل العلمي)؟ للإجابة عن هذا السؤال تم حساب المتوسطات الحسابية والانحرافات المعيارية لتقديرات أفراد عينة الدراسة على مقياس قبول الذات لمتغيري (العمر ، المؤهل العلمي). والجدول (3) يبين ذلك. 


\begin{tabular}{|c|c|c|c|c|}
\hline \multicolumn{5}{|c|}{ حتغيري (العمر، المؤهل العلمي). } \\
\hline الانحراف المعياري & المتوسط الحسابي & العدد الع & فئات المتغير & المتغير \\
\hline 0.26 & 2.26 & 25 & أقل من 30 سنة & \multirow{4}{*}{ العمر } \\
\hline 0.23 & 2.31 & 27 & من 31إلى 40 سنة & \\
\hline 0.21 & 2.33 & 13 & أكثر من 41 سنة & \\
\hline 0.24 & 2.31 & 65 & الكلي & \\
\hline 0.21 & 2.32 & 13 & اساسي & \multirow{4}{*}{ المؤهل العلمي } \\
\hline 0.23 & 2.31 & 35 & ثانوي & \\
\hline 0.28 & 2.28 & 17 & جامعي & \\
\hline 0.24 & 2.29 & 65 & الكلي & \\
\hline
\end{tabular}

يبين الجدول (3) وجود فروق ظاهرية بين المتوسطات الحسابية والانحرافات المعيارية لتقديرات أفراد عينة الدراسة على مقياس قبول الذات حسب متغيري (العمر، المؤهل العلمي). وللتحقق من دلالة الفروق بين المتوسطات الحسابية تم استخدام تحليل التباين الثلاثي (2 Way ANOVA). والجدول (4) يوضح ذلك.

الجدول (4): تحليل التباين (2 Way ANOVA) لتقديرات أفراد عينة الدراسة على مقياس قبول الذات حسب متغيري

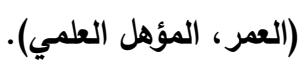

\begin{tabular}{|c|c|c|c|c|c|}
\hline الإحصائية & قالمحسوبة & متوسط المربعات & درجات الحرية & مجموع المربعات & مصدر التباين \\
\hline .412 & .901 & .054 & 2 & .108 & العمر \\
\hline \multirow[t]{3}{*}{.291} & 1.262 & .076 & 2 & .151 & المؤهل العلمي \\
\hline & & .060 & 60 & 3.599 & الخطأ \\
\hline & & & 64 & 3.761 & المجموع المعدل \\
\hline
\end{tabular}

( $\alpha=0.05$ * ذات دلالة إحصائية عند مستوى الدلالة

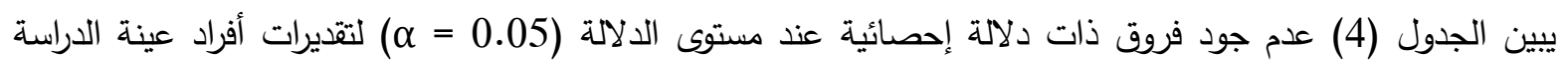
على مقياس قبول الذات حسب متغيري العمر والمؤهل العلمي؛ حيث كانت قيمة (ف) المحسوبة لمتغير العمر (0.901) والدلالة الإحصائية (412.)، وهي أقل من (0.05) عند درجة الحرية (2). وقيمة (ف) المحسوبة لمتغير المؤهل العلمي (1.262) والدلالة الإحصائية (0.291)، وهي أقل من (0.05) عند درجة الحرية (2). وقد تعزى هذه النتيجة إلى أن الإناث يتعرضن

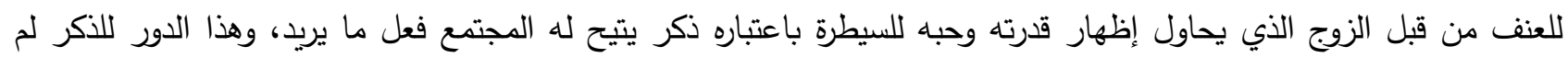

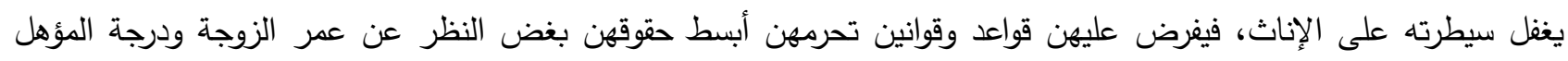

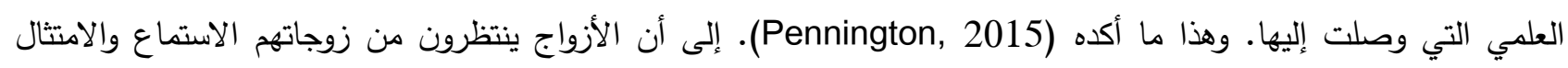

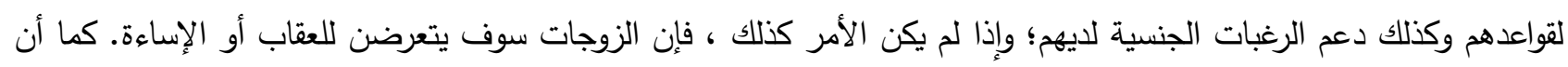

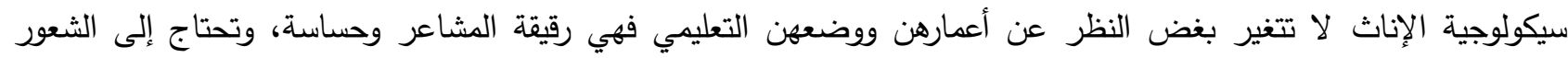
بالأمن والحنان والقبول، ومن هنا يفرض الذكر هيمنته عليهن، وعليهن الالتزام بالنقاط التي حددها الذكر لهن، وأن تجاوزهن لهذه

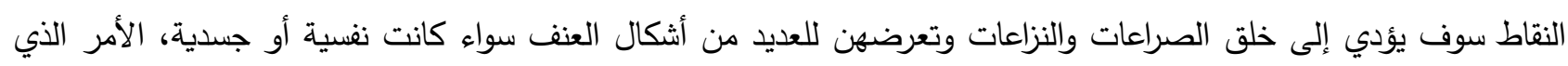
يؤدي إلى تدني مستوى قبولهن لذواتهن. كما قد تعزى هذه النتيجة إلى السيناريوهات الاجتماعية التي تستوعبها الفتيات في بداية

360 IUG Journal of Educational and Psychology Sciences (Islamic University of Gaza) / CC BY 4.0 
العمر من خلال تعرضهن لضغوط اجتماعية للتخلي عن ذواتهم الأصلية جانباً، ويصبحن ما يريدهن المجتمع أن يكن عليه. وتتفق

نتيجة هذه الدراسة مع نتيجة دراسة (Hernandez, 2014)، بينما تختلف هذه النتيجة مع نتيجة دراسة (Rababah, 2017).

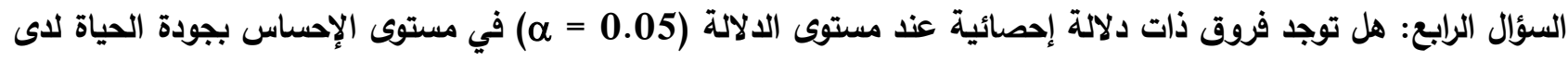
النساء المعنفات تعزى لمتغيري (العمر، المؤهل العلمي)؟ للإجابة عن هذا السؤال تم حساب المتوسطات الحسابية والانحرافات المعيارية لتقديرات أفراد عينة الدراسة على أبعاد مقياس الإحساس بجودة الحياة حسب متغيري (العمر ، المؤهل العلمي). والجدول (5) يبين ذلك.

\begin{tabular}{|c|c|c|c|c|c|c|c|}
\hline \multicolumn{8}{|c|}{ الجدول (5): المتوسطات الحسابية والانحرافات المعيارية لتقديرات أفراد عينة الاراسة على أبعاد مقياس الإحساس بجودة } \\
\hline الكلي & 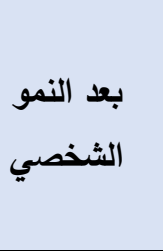 & بعد التمكن & الاستقلالية & بعد الههف في & الحسابي المتوسط المعياري & المتغير & المتغير \\
\hline 2.18 & 2.15 & 2.17 & 2.18 & 2.22 & الحستوسط & \multirow{2}{*}{ أقل من 30} & \multirow{6}{*}{ العمر } \\
\hline 0.14 & 0.32 & 0.26 & 0.30 & 0.24 & الانحراف & & \\
\hline 2.18 & 2.12 & 2.19 & 2.19 & 2.23 & الحستيط & \multirow{2}{*}{ من 31 إلى 40 سنة } & \\
\hline 0.14 & 0.32 & 0.25 & 0.25 & 0.25 & 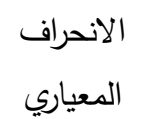 & & \\
\hline 2.20 & 2.23 & 2.23 & 2.08 & 2.26 & الحسابي المتوسط & \multirow{2}{*}{ أكثر من 41 سنة } & \\
\hline 0.16 & 0.29 & 0.19 & 0.35 & 0.18 & الانحراف المعياري & & \\
\hline 2.19 & 2.18 & 2.24 & 2.22 & 2.14 & الحسابي & \multirow{2}{*}{ اساسي } & \multirow{6}{*}{ العلمي } \\
\hline 0.11 & 0.31 & 0.17 & 0.23 & 0.30 & الانحراف المعياري & & \\
\hline 2.18 & 2.16 & 2.20 & 2.16 & 2.23 & الحسابي المتوسط & \multirow{2}{*}{ ثانوي } & \\
\hline 0.14 & 0.31 & 0.24 & 0.29 & 0.23 & الانعراف المعياري & & \\
\hline 2.17 & 2.14 & 2.14 & 2.13 & 2.30 & الحستوسط & \multirow[t]{2}{*}{ جامعي } & \\
\hline 0.16 & 0.33 & 0.30 & 0.34 & 0.14 & الانحراف & & \\
\hline
\end{tabular}




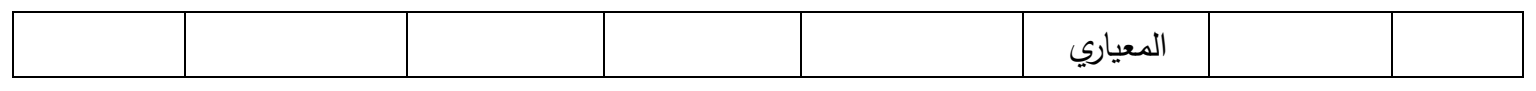

يبين الجدول (5) وجود فروق ظاهرية بين المتوسطات الحسابية والانحرافات لتقديرات أفراد عينة الدراسة على أبعاد مقياس الإحساس بجودة الحياة حسب متغيري (العمر، المؤهل العلمي). وللتحقق من دلالة الفروق بين المتوسطات الحسابية تم استخدام تحليل التباين المتعدد (MANOVA). والجدول (6) يوضح ذلك.

\begin{tabular}{|c|c|c|c|c|c|c|}
\hline \multicolumn{7}{|c|}{ جدول (6): اختبار تحليل التباين المتعدد (MANOVA) لأثر متغيري العمر والمؤهل العلمي على تقديرات عينة الدراسة على } \\
\hline الاحصائية & 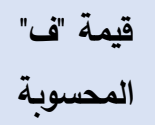 & متوسط & 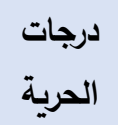 & 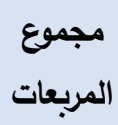 & المجالات & مصدر التباين \\
\hline .811 & .210 & .012 & 2 & .024 & الهدف في الحياة & \multirow{5}{*}{ فيلكس لمبادا= 926.} \\
\hline .472 & .761 & .069 & 2 & .138 & الاستقلالية & \\
\hline .382 & .977 & .060 & 2 & .121 & التمكن البيئي & \\
\hline .545 & .613 & .064 & 2 & .129 & النمو الثخصي & \\
\hline .701 & .357 & .008 & 2 & .016 & الكلي & \\
\hline .195 & 1.681 & .094 & 2 & .188 & الهدف في الحياة & \multirow{5}{*}{ فيلكس لمبادا = 1956.} \\
\hline .686 & .380 & .035 & 2 & .069 & الاستقلالية & \\
\hline .280 & 1.302 & .081 & 2 & .161 & التمكن البيئي & \\
\hline .836 & .179 & .019 & 2 & .038 & النمو الثخصي & \\
\hline \multirow[t]{11}{*}{.761} & .274 & .006 & 2 & .012 & الكلي & \\
\hline & & .056 & 60 & 3.360 & الهدف في الحياة & \multirow{5}{*}{ الخطأ } \\
\hline & & .091 & 60 & 5.455 & الاستقلالية & \\
\hline & & .062 & 60 & 3.714 & التمكن البيئي & \\
\hline & & .105 & 60 & 6.311 & النمو الثخصي & \\
\hline & & .023 & 60 & 1.362 & الكلي & \\
\hline & & & 64 & 3.566 & الهدف في الحياة & \multirow{5}{*}{ المجموع المعدل } \\
\hline & & & 64 & 5.643 & الاستقلالية & \\
\hline & & & 64 & 3.909 & التمكن البيئي & \\
\hline & & & 64 & 6.454 & النمو الثخصي & \\
\hline & & & 64 & 1.382 & الكلي & \\
\hline
\end{tabular}

* ذات دلالة إحصائية عند مستوى الدلالة (م) (م)

يتبين من الجدول (6) عدم وجود فروق ذات دلالة إحصائية عند مستوى (0.05 ) م ه) لتقديرات أفراد عينة الدراسة على أبعاد مقياس الإحساس بجودة الحياة حسب متغيري (العمر، المؤهل العلمي). وربما تعود هذه النتيجة إلى أن المرأة مهما تقدمت

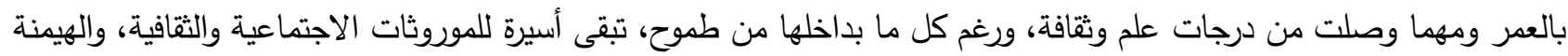
الذكورية والتتشئة الاجتماعية، وعندما تتعرض للعنف يؤدي ذلك بها لعدم الاستقلالية، ونقص الكفاية الذاتية، ونمو شخصي أقل، وعدم وجود علاقات إيجابية مع الآخرين، وتدني تقبل الذات، بالإضافة إلى حرمانهن من تحقيق أهم أهداف الحياة في تكوين الأسرة 
التي تتمثل في الأمومة وتربية الأولاد وتحقيق الكفاية الذاتية والنمو الشخصي، وهذه من أهم مقومات الشعور بالسعادة، الأمر الذي

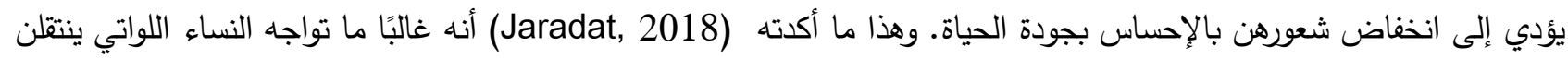

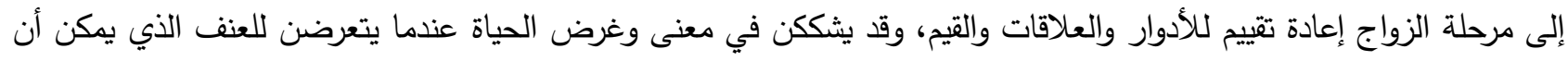

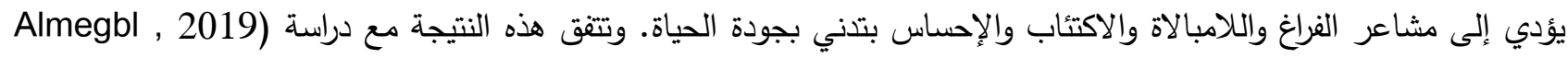

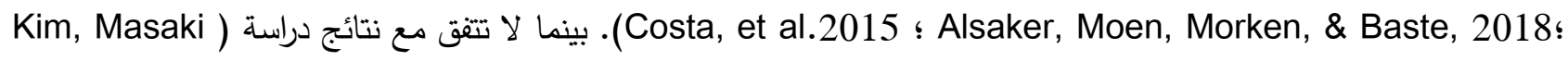

.(\& Mehrotra, 2010

السؤال الخامس: هل هناك علاقة دالة احصائياً عند مستوى الدلالة (0.05 = م) بين قبول الذات والإحساس بجودة الحياة لاى النساء المعنفات؟ للإجابة عن هذا السؤال تم استخراج معامل ارتباط بيرسون بين مستوى قبول الذات لاى النساء المعنفات

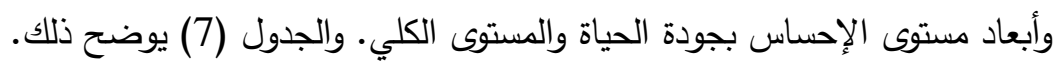

\begin{tabular}{|c|c|}
\hline \multicolumn{2}{|c|}{ الألمستوى اللى النساء المعنفات وأبعاد مستوى الإحساس بجودة الحياة } \\
\hline مقياس قبول الذات & أبعاد مقياس جودة الحياة \\
\hline$* 0.64$ & الهدف في الحياة \\
\hline$* 0.56$ & الاستقلالية \\
\hline$* 0.65$ & التمكن البيئي \\
\hline$* 0.59$ & النمو الثخصي \\
\hline$* 0.53$ & المقياس الكلي \\
\hline
\end{tabular}

* ذات دلالة إحصائية عند مستوى الدلالة (م=05)

يتبين من الجدول (7) وجود علاقة ايجابية دالة إحصائياً بين بين قبول الذات والإحساس بجودة الحياة لدى النساء

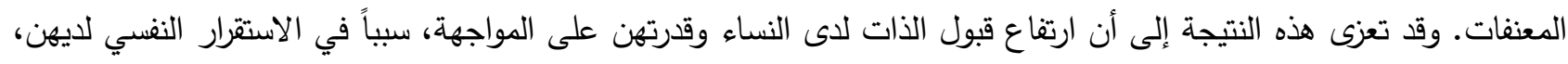
وهذا يساعد في تقيمهن لجوانب الحياة بشكل جيد ومتقائل، مما يحقق لديهن القبول وتزويدهن بالقدرة على المواجهة وتحدي القياء

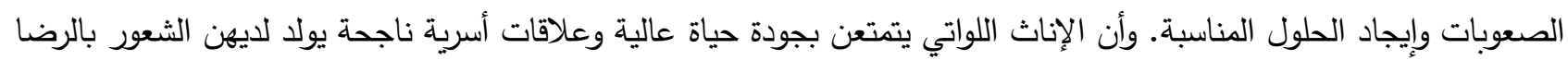
والسعادة والارتياح النفسي مما يولد لديهن قبول ذاتي ويعملن على تطوير استراتيجيات مواجهة يساعدهن على ايجاد توازن إيجابي يسوده الهدوء والاستقرار • وهذا ما أكده (Bernard, 2013) إلى أن قبول الذات يخفف من التأثير السلبي للإيذاء الجسدي والنفيسي علئي ويتم تتشيطه لمساعدة النساء المعنفات على الحفاظ على نظرة ذاتية إيجابية من خلال تجاربهن الإيجابية في العمل وتربية الأطفال

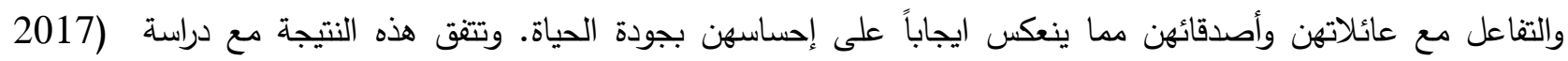

.(Broady \& Neff, 2009, Venter, 2011؛Mohammed, التوصيات: بناءً على نتائج الدراسة يوصي الباحثان بالآتي: - - نظرًا للارتباط الكبير بين العنف وقبول الذات والإحساس بجودة الحياة، فمن المستحسن أن يقوم مقدمو الرعاية بمساعدة النساء المعنفات على زيادة وعيهن بالكيفية التي قد يؤدي بها الإيذاء النفسي إلى الشعور بالنقص وعدم القدرة والعجز والتأثير سلبًا على قرارات الحياة المهمة. - - تكثيف حملات التوعية والخدمات المقدمة من مؤسسات حماية الأسرة من أجل زيادة معرفة المرأة بحقوقها، وكيفية التعامل مع العنف الموجه نحوها. - - العمل على ضرورة إعداد برامج إرشادية ونفسية تهتم بتمية الجوانب الإيجابية لدى النساء المعنفات لمساعدتهن في التغلب 


$$
\text { - ملى ت إجراء مزيداً من الدراسات والأبحاث حول الإحساس بجودة الحياة الناتج عن العنف. }
$$

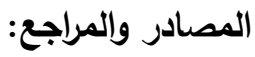

Abadi M. N. L, Ghazinour M, Nojomi M, Richter J. (2012). The buffering effect of social support between domestic violence and self-esteem in pregnant women in Tehran, Iran. Journal of Family Violence. 27.(3):225-231.

Alhalal, E., Ford-Gilboe, M., Kerr, M., \& Davies, L. (2012). Identifying factors that predict women's inability to maintain separation from an abusive partner. Issues in Mental Health Nursing, 33(12), 838-50.

Almegbl, H. (2019). The Relationship Between Quality Of Life And Symptoms Of Post-Traumatic Stress Disorder In Battered Women (In Arabic). Unpublished MA Thesis At Yarmouk University. Irbid, Jordan.

Alsaker, K., Moen, B. E., Kristoffersen, K., Social, S., \& May, N. (2015). Health-related quality of life among abused women one year after leaving a violent partner. Social Indicators Research, 86(3), 497-509.

Alsaker,K., Moen, B., Morken, T., Baste.,V.(2018).Intimate partner violence associated with low quality of life-a cross-sectional study. BMC Women's Health.18(148), 1-7.

Anderson, K. M., Renner, L. M., \& Danis, F. S. (2012). Recovery Resilience and Growth in the Aftermath of Domestic Violence. Violence Against Women, 18(11), 1279-1299.

Barnett, O. W. (2001). Why battered women do not leave, part 2: External inhibiting factorssocial support and internal inhibiting factors. Trauma, Violence, \& Abuse, 2(1), 3-35.

Bernard, M.(2013).The Strength of Self-Acceptance. Theory, Practice and Research. Springer New York Heidelberg Dordrecht London.

Beydoun, H. A., Williams, M., Beydoun, M. A., Eid, S. M., \& Zonderman, A. B. (2017). Relationship of physical intimate partner violence with mental health diagnoses in the nationwide emergency department sample. Journal of Women's Health, 26(2), 414-151.

Black, M.C., Basile, K.C., Breiding, M.J., Smith, S.G., Walters, M.L., Merrick, M.T., Chen, J., \& Stevens, M.R. (2011). The national intimate partner and sexual violence survey (NISVS): 2010 summary report. Atlanta, GA: National Center for Injury Prevention and Control, Centers for Disease Control and Prevention.

Committee On The Elimination Of Discrimination Against Women (2012). The Convention On The Elimination Of All Forms Of Discrimination Against Women. Fifty-First Session. United Nations (In Arabic). (February 13 - March 2) 2012.

Costa, D., Hatzidimitriadou, E., Ioannidi-Kapolou, E., Lindert, J., Soares, J., Sundin, O., Toth, O. and Barros, H. (2015) Intimate partner violence and health-related quality of life in European men and women: findings from the DOVE study. Quality of Life Research, 24 (2). 463-471. ISSN 0962-9343.

Council of Europe.(2011) Council of Europe Convention on preventing and combating violence against women and domestic violence (Vol. CETS no.210). 2011.

Department Of Statistics (2018). Jordan Population And Family Health Survey 2017-2018. Oman Jourdan. Retrieved July 1, 2020. From Http://Dosweb.Dos.Gov.Jo/Ar/Dhs-2017/

Duffy, L. (2015). Achieving a sustainable livelihood after leaving intimate partner violence: Challenges and opportunities. Journal of Family Violence, 30(4), 403-417.

Edwards, K. M., Dardis, C. M., Sylaska, K. M., \& Gidycz, C. A. (2015). Informal social reactions to college women's disclosure of intimate partner violence: Associations with psychological and relational variables. Journal of Interpersonal Violence, 30(1), 25-44. 
Ferriss, A.(2010). Approaches to Improving the Quality of Life. How to Enhance the Quality of Life. Springer Science+Business Media B.V.

Fung,. C.(2011). Exploring Individual Self-Awareness As It Relates To Self-Acceptance And The Quality Of Interpersonal Relationships. Degree of Master theses. Pepperdine University.

Georgiou., J.(2009). Quality of Life Indicators: The Objective-Subjective Interrelationship That Exists within One's 'Place of Residence' in Old Age. Asian Social Science. 5 ( 9),3-20.

Gharacheh, M, Azadi,S, Mohammadi, N, Montazeri, S, \& Khalajinia, Z.(2016). Domestic Violence during Pregnancy and Women's Health-Related Quality of Life. Global Journal of Health Science; 8 (2).27- 34.

Gilroy, H., Nava, A., Maddoux, J., McFarlane, J., Symes, L., Koci, A., \& Fredland, N. (2014). Poverty, partner abuse, and women's mental health: New knowledge for better practice. Journal of Social Service Research, 41(2), 145-157.

Goodman, L. A., \& Smyth, K. F. (2011). A call for a social network-oriented approach to services for survivors of intimate partner violence. Psychology of Violence, 1(2), 79-92.

Gupta, J., Falb, K. L., Ponta, O., Xuan, Z., Campos, P. A., Gomez, A. A., ... Olavarrieta, C. D. (2017). A nurse-delivered, clinic-based intervention to address intimate partner violence among low-income women in Mexico City: Findings from a cluster randomized controlled trial. BMC Medicine, 15(1), 1-12.

Hamden-Mansour, A., Arabiat, D., Sato, T., Obaid, B., \& Imoto, A. (2011). Marital abuse and psychological well-being among women in the southern region of Jordon. Journal of Transcultural Nursing, 22 (3), 265-273.

Hernandez, P. (2014)."The Right Reflection: Improving Women's Self-Acceptance" .Master of Applied Positive Psychology. (MAPP) Capstone Projects.

Howatt., W.(2012). Roles of Internal Locus of Control and Self-Efficacy on Managing Job Stressors and Ryff's Six Scales of Psychological Well-Being. Degree of Doctor. Walden University.

Jaradat, D.(2018). "Women's Quality of Life After Leaving an Abusive Relationship: The Effects of Past and Ongoing Intimate Partner Violence, Mastery and Social Support" Electronic. degree of Doctor. Western University.

Kharabsheh, S. (2013). The Effectiveness Of A Counseling Program Based On The Existential Theory In Promoting Psychological Resilience, Self-Acceptance And Family Relationships Among A Sample Of Women With Breast Cancer In Jordan (In Arabic). Unpublished Phd Thesis. Yarmouk University.

Kim, M., Masaki, B., \& Mehrotra, G. (2010). A lily out of the mud: Domestic violence in Asian \& Pacific Islander communities. In L. Lockhart \& F. Dania (Eds.), Domestic violence: Intersectionality and culturally competent practice, (pp. 134-170). New York, NY: Columbia University Press.

Larsen, M., Krohn, J., Püschel, K., \& Seifert, D. (2014). Experiences of health and health care among women exposed to intimate partner violence: qualitative findings from Germany. Health Care for Women International, 35(4), 359-379

Leung, T. W., Leung, W. C., Ng, E. H. Y., \& Ho, P. C. (2005). Quality of life of victims of intimate partner violence. International Journal of Gynaecology and Obstetrics: The Official Organ of the International Federation of Gynaecology and Obstetrics, 90(3), 258-62.

Lucena, K, Vianna. R, Nascimento. J, Campos. H, Oliveira E. (2017). Association between domestic violence and women's quality of life. Rev. Latino-Am. Enfermagem.;25:e2901, 1-8.

Michael, J, (2014). Male Violence Prevention Project: A Grant Proposal. A Thesis Presented to the School of Social Work, California State University, Long Beach, UMI Number: 1571454.

Mohammed, H. M. (2016). Resilience as moderator variable to the relationship between burnout and marital satisfaction among workers of married couples in Egypt. Indian Journal of Health and Wellbeing, 7(5), 493-499.

365 IUG Journal of Educational and Psychology Sciences (Islamic University of Gaza) / CC BY 4.0 
Monnickendam, M., \& Berman, Y. (2008,). An empirical analysis of the interrelationship between components of the social quality theoretical construct. Social Indicators Research, 86(3) 525538.

Neff, L. A., \& Broady, E. F. (2011). Stress resilience in early marriage: Can practice make perfect? Journal of Personality and Social Psychology, 101(5), 1050-1067.

Pennington, L. (2015). " From Housewife to Breadwinner": Khmer Women Changing Places and Gender Roles Following the Cambodian Genocide: Degree of Master .California State University, Long Beach.

Rababa'a, M. (2017). The Relationship Of Quality Of Life, Social Acceptance And Coping Strategies Among Battered Females. (In Arabic). The International Interdisciplinary Journal Of Education. 6. (11) 60- -80.

Ritsner, M., Kurs, R., Kositizky, H., Ponizovsky, A., \& Modai, I. (2002). Subjective quality of life in severely mentally ill patients: A comparison of two instruments. Quality of Life Research, $11,(6), 553-561$.

Rizo, C. F. (2016). Intimate partner violence related stress and the coping experiences of survivors: There's only so much a person can handle. Journal of Family Violence, 31(5), 581593.

Tavoli, Z, Tavoli, A., Amirpour, R., Hosseini.,R \& Montazeri, A. (2016). Quality of life in women who were exposed to domestic violence during pregnancy. BMC Pregnancy and Childbirth. 16(19), 1-7.

Tsirigotis, K., \& Łuczak, J. (2018). Resilience in women who experience domestic violence. Psychiatric quarterly, 89(1), 201-211.

Vives-Cases, C., Ruiz-Cantero, M. T., Escriba-Aguir, V.,Miralles, J. J. (2010).The effect of intimate partner violence and other forms of violence against women on health .Journal of Public Health, 33(1), 15-21.

Watkins, L. E., Jaffe, A. E., Hoffman, L., Gratz, K. L., Messman-Moore, T. L., \& DiLillo, D. (2014). The longitudinal impact of intimate partner aggression and relationship status on women's physical health and depression symptoms. Journal of Family Psychology, 28(5), 655-665.

WHOQOL Group.( 1998) Development of the World Health Organization WHOQOL-BREF quality of life assessment. Psychology Med;28(3),551-558.

WHOQOL-BREF.(1996). Introduction, Administration, Scoring And Generic Version Of The Assessment. World Health Organization Geneva.

World Health Organization. (2016). Violence against women. Retrieved April 20, 2020. From: https://www.who.int/mediacentre/factsheets/fs239/en 